\title{
Assessment of the sensory threshold in patients with atopic dermatitis and psoriasis
}

\author{
Magdalena Krzyżanowskaํ, Katarzyna Muszer ${ }^{1}$, Konrad Chabowski ${ }^{1,2}$, Adam Reich ${ }^{1}$ \\ ${ }^{1}$ Department of Dermatology, Venereology and Allergology, Wroclaw Medical University, Wroclaw, Poland \\ Head of the Department: Prof. Jacek C. Szepietowski MD, PhD \\ ${ }^{2}$ Faculty of Microsystem Electronics and Photonics, Wroclaw University of Technology, Wroclaw, Poland \\ Head of the Department: Prof. Teodor Gotszalk
}

Postep Derm Alergol 2015; XXXII, 2: 94-100

DOI: $10.5114 /$ pdia.2014.44013

\begin{abstract}
Introduction: Atopic dermatitis $(A D)$ and psoriasis are chronic inflammatory skin diseases frequently accompanied by itching. The exact pathogenesis of dermatological pruritus remains unknown, but it is believed that altered skin innervation may play a role.

Aim: The assessment of the sensory threshold in $A D$ and psoriasis in relation to pruritus experienced by patients. Material and methods: $A$ total of 18 subjects with AD, 20 with psoriasis and 49 healthy controls were exposed to alternating current generated by the current source. A selected preset of current frequencies (ranging from $5 \mathrm{~Hz}$ to $2000 \mathrm{~Hz}$ ) allowed a selective stimulation of different nerve endings (A $\beta, A \delta$ and C-type). Pruritus severity was measured with visual analogue scale (VAS) and an itch questionnaire developed in house. All results were analyzed statistically.

Results: Sensory thresholds within the uninvolved skin of AD or psoriasis patients were significantly higher than in healthy volunteers $(p<0.001)$, and no significant differences were found between AD and psoriasis $(p>0.05)$. Similarly, sensory thresholds within the diseased skin of AD or psoriasis were significantly higher than in the normal skin $(p<0.01)$, and patients with psoriasis had also a significantly higher threshold than AD individuals $(p<0.05)$. The sensory threshold inversely correlated with pruritus severity in $A D$ and psoriasis and the highest correlation was found for $5 \mathrm{~Hz}$ frequency predominantly stimulating C fibers (VAS: $R=-0.32, p<0.05$; pruritus questionnaire: $R=0.54, p<0.001$ ).

Conclusions: Evaluation of the sensory threshold may be a valuable tool for pruritus assessment, but further studies are still warranted.
\end{abstract}

Key words: pruritus, itch, diagnostics, skin diseases.

\section{Introduction}

Chronic inflammatory skin diseases, like atopic dermatitis (AD) or psoriasis, are frequently accompanied by itching, a subjective sensation evoking a desire to scratch. In many patients it is an extremely distressing and bothering ailment, making it a very relevant clinical problem [1-3]. Due to its subjective nature, the objective and valid assessment of pruritus remains a significant challenge [4]. The pathophysiology of chronic pruritus in skin diseases is also still not precisely elucidated despite the fact that a number of substances have been postulated as possible itch mediators [5]. However, it was observed that patients with $A D$ or psoriasis suffering from pruritus demonstrated increased nerve density within the epidermis and dermis [6-9]. Interestingly, asreported by Urashima and Nahara [6], the diameter of skin nerve fibers in AD was also much larger, because of the large number of axons in each nerve fiber. It was postulated that an abnormal skin innervation in patients with chronic pruritus might be responsible for their higher sensitivity to itchy stimuli due to lowering of itch threshold [1013]. It was observed that tactile threshold in patients with nodular prurigo, a chronic itchy skin condition, was lower than in controls and this phenomenon was reversed by capsaicin suggesting neuropeptide involvement, mainly substance P [10]. Furthermore, the basal skin blood flow

Address for correspondence: Prof. Dr Adam Reich, Department of Dermatology, Venereology and Allergology, Wroclaw Medical University, 1 Chałubinskiego St, 50-368 Wroclaw, Poland, phone: +48 605076 722, fax: +48 7132709 99, e-mail: adi_medicalis@go2.pl Received: 11.02.2014, accepted: 20.03.2014. 
level was more fluctuating in itchy areas than in healthy skin areas in nodular prurigo patients suggesting an abnormal spontaneous activity of nociceptive peripheral nerve fibers and a consequent release of vasoactive agents from their terminals (axon reflex) [10]. People with chronic pruritus may be even prone to feel itch after stimuli that normally do not evoke pruritus. For instance, it was shown that painful stimuli evoked itch rather than pain in $A D$ patients suggesting the presence of a central sensitization phenomenon [14].

Several studies demonstrated that electric stimulation might evoke pruritus in patients with chronic itch $[15,16]$. It was also shown that different frequencies of electric stimuli may activate different nerves subtypes [17]. Many studies indicated the role of transcutaneous electrical nerve stimulation to specify nerve function in various types of peripheral neuropathies [18-23]. Taking into account the ease of evoking electric stimuli in clinical settings $[16,24]$, it seems interesting to test whether measurement of the threshold for electrical stimuli might be a helpful procedure in evaluating pruritus intensity.

\section{Aim}

To verify this hypothesis we performed a study to assess the sensory threshold for electric stimuli in $A D$ and psoriasis in relation to perceived pruritus.

\section{Material and methods}

\section{Patients}

A total of 87 subjects including 18 patients with $A D, 20$ with psoriasis and 49 healthy volunteers were recruited into the study. Each participant after getting a detailed explanation about the study aim signed an informed consent form prior to any study procedure. Detailed demographic and clinical characteristics of the studied population are demonstrated in Table 1.

\section{Study design}

The study was approved by the Bioethical Committee of Wroclaw Medical University. All subjects underwent thorough anamnesis and physical examination. Atopic dermatitis severity was assessed according to Scoring of

Table 1. Demographic and clinical characteristics of studied subjects (results demonstrated as cardinality and frequencies or means \pm standard deviations)

\begin{tabular}{|c|c|c|c|c|}
\hline Parameter & $\begin{array}{l}\text { Patients with } \\
\text { atopic dermatitis }\end{array}$ & $\begin{array}{l}\text { Patients with } \\
\text { psoriasis }\end{array}$ & Controls & Value of $p$ \\
\hline$N$ & 18 & 20 & 49 & - \\
\hline \multicolumn{5}{|l|}{ Gender: } \\
\hline Males & $8(44.4)$ & $16(80.0)$ & $31(63.3)$ & $<0.01$ \\
\hline Females & $10(55.6)$ & $4(20.0)$ & $18(36.7)$ & \\
\hline Age [years] & $37.8 \pm 14.4$ & $44.6 \pm 12.9$ & $26.3 \pm 9.6$ & $<0.001$ \\
\hline \multicolumn{5}{|l|}{ Education: } \\
\hline Primary school & $0(0)$ & $1(5.0)$ & $1(2.0)$ & 0.24 \\
\hline High school & $14(77.8)$ & $13(65.0)$ & $43(87.8)$ & \\
\hline University & $4(22.2)$ & $6(30.0)$ & $5(10.2)$ & \\
\hline \multicolumn{5}{|l|}{ Place of living: } \\
\hline Village & $2(11.1)$ & $0(0)$ & $9(18.4)$ & $<0.001$ \\
\hline Small town & $10(55.6)$ & $14(70.0)$ & $6(12.2)$ & \\
\hline Big city & $6(33.3)$ & $6(30.0)$ & $34(69.4)$ & \\
\hline Disease duration [years] & $25.4 \pm 16.5$ & $20.8 \pm 17.1$ & - & 0.4 \\
\hline Duration of disease exacerbation [months] & $3.1 \pm 3.1$ & $8.3 \pm 8.9$ & - & 0.03 \\
\hline \multicolumn{5}{|l|}{ Pruritus intensity: } \\
\hline VAS currently & $3.6 \pm 2.8$ & $3.4 \pm 2.4$ & - & 0.87 \\
\hline $\mathrm{VAS}_{\max }$ & $6.4 \pm 2.5$ & $4.8 \pm 2.8$ & - & 0.07 \\
\hline Pruritus questionnaire & $15.2 \pm 3.8$ & $12.0 \pm 4.4$ & - & 0.02 \\
\hline \multicolumn{5}{|l|}{ Disease severity: } \\
\hline SCORAD & $50.8 \pm 16.6$ & - & - & - \\
\hline PASI & - & $19.6 \pm 10.0$ & - & \\
\hline
\end{tabular}

Results presented as mean \pm standard deviation or $n(\%)$. 
AD (SCORAD) [25], while psoriasis severity according to Psoriasis Area and Severity Index (PASI) [26]. Pruritus intensity was evaluated with the 10-point Visual Analogue Scale (VAS) [27, 28] and the validated itch questionnaire developed on site [29]. With VAS patients assessed pruritus intensity at the time of examination $\left(V S_{\text {current }}\right)$ and maximal itch intensity within the previous 3 days $\left(V_{\text {max }}\right.$ ). Scoring of itch questionnaire with VAS VAS $_{\text {current }}$ and itch questionnaire: $\rho=0.45, p<0.01$ VAS $_{\max }$ and itch questionnaire: $\rho=0.47, p<0.01$.

\section{Assessment of the sensory threshold}

Participants were exposed to the alternating square wave current of following frequencies: $5 \mathrm{~Hz}, 250 \mathrm{~Hz}$, and $2000 \mathrm{~Hz}$ to obtain stimulation of unmyelinated C (C), small myelinated $A(A \delta)$ and large myelinated $A(A \beta)$ nerve fibres, respectively. Prior to measurements, the skin was degreased with ethanol and next the electrodes were attached to the palmar surface of the forearm. Both, involved and uninvolved skin was tested in AD and psoriasis patients. The alternating current of defined frequency was generated by the current source constructed by the authors (KC and AR) (Figure 1, pending patent application P. 400563 (PK/1662/AW)). The current intensity was gradually increased with manual regulation. Patients were instructed to indicate the moment of the first current perception. Current intensity was measured with an ammeter integrated with the current source. Current frequencies were tested in a random order.

\section{Statistical analysis}

Each measurement was performed in triplicate and the mean value of these three measurements was used for further analysis. All results were analysed statistically using Statistica ${ }^{\circledR} 10.0$ (StatSoft, Cracow, Poland). The significance of the observed relationships of studied parameters were determined by the analysis of variance (ANOVA), with paired and unpaired Student's $t$ test or Spearman's rank correlation test. A $p$-value lower than 0.05 was considered as statistically significant.

\section{Results}

\section{Measurement of the sensory threshold in healthy controls}

The mean sensory thresholds in healthy subjects at $5 \mathrm{~Hz}, 250 \mathrm{~Hz}$ and $2000 \mathrm{~Hz}$ current frequency were 118.1 $\pm 25.5 \mu \mathrm{A}, 192.9 \pm 24.5 \mu \mathrm{A}$ and $687.1 \pm 86.0 \mu \mathrm{A}$, respectively. Women had a significantly lower sensory threshold at $5 \mathrm{~Hz}$ compared to men (Table 2 ). In addition, patients living in villages showed significantly higher mean sensory thresholds than people living in towns or cities. There was no significant relationship between the sensory threshold level and age of healthy volunteers (Table 2).

\section{Sensory threshold in atopic dermatitisand psoriasis}

Patients with AD demonstrated a significantly higher mean sensory threshold for electric stimuli when com-

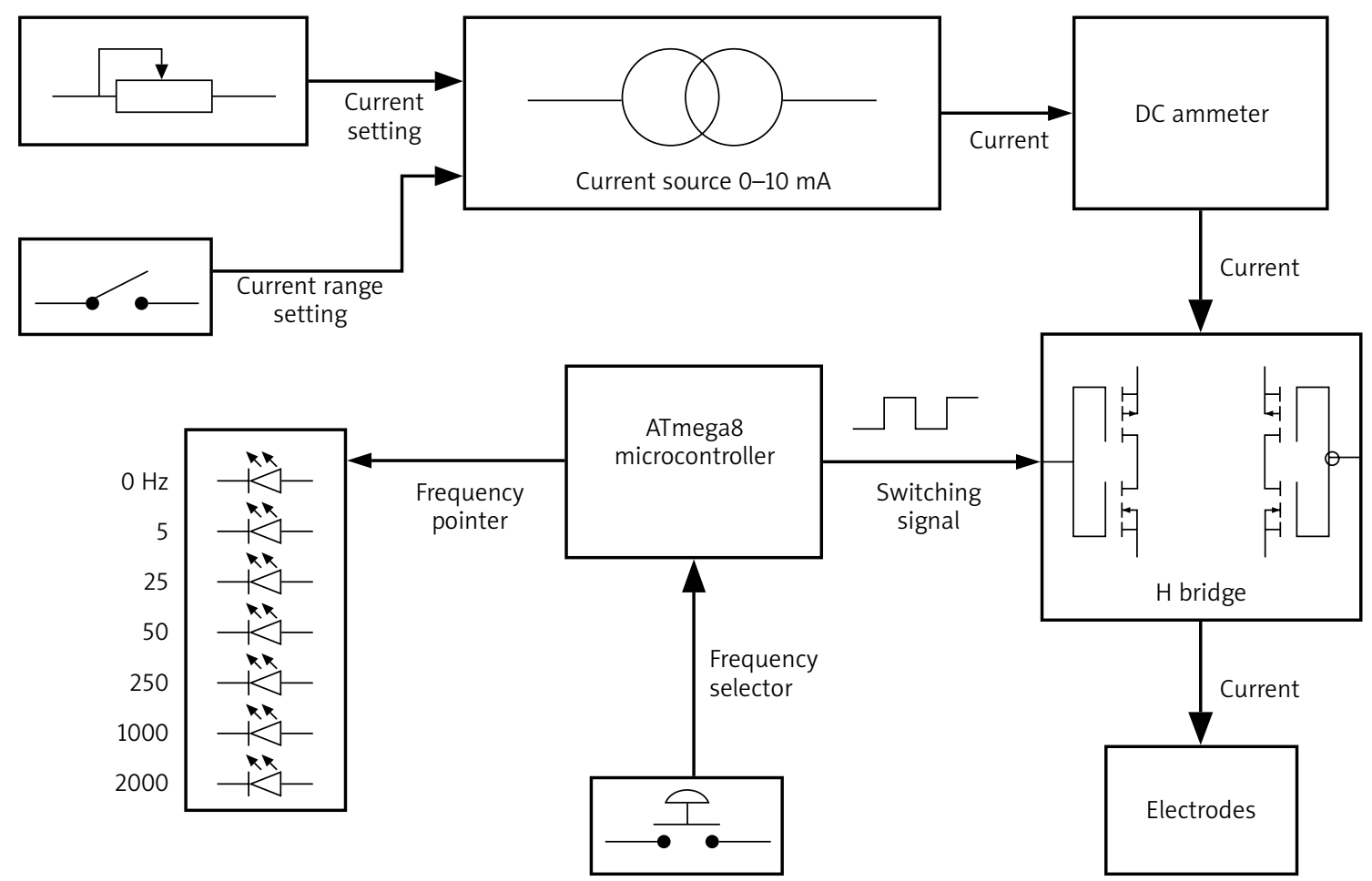

Figure 1. Schematic overview of the current source constructed for assessment of the sensory threshold 
Table 2. Mean sensory threshold levels $(\mu \mathrm{A})$ for different current frequencies in healthy subjects

\begin{tabular}{|c|c|c|c|}
\hline \multirow[t]{2}{*}{ Parameter } & \multicolumn{3}{|c|}{ Current frequency } \\
\hline & $5 \mathrm{~Hz}$ & $250 \mathrm{~Hz}$ & $2000 \mathrm{~Hz}$ \\
\hline \multicolumn{4}{|l|}{ Gender: } \\
\hline Females & $74.9 \pm 20.4$ & $157.6 \pm 14.8$ & $589.3 \pm 89.5$ \\
\hline \multirow[t]{2}{*}{ Males } & $192.6 \pm 56.7$ & $253.7 \pm 59.9$ & $864.2 \pm 175.2$ \\
\hline & $p=0.02$ & $p=0.47$ & $p=0.17$ \\
\hline \multicolumn{4}{|l|}{ Place of living: } \\
\hline Village & $292.0 \pm 108.1$ & $318.9 \pm 98.1$ & $906.5 \pm 234.5$ \\
\hline Small town & $100.7 \pm 31.5$ & $206.4 \pm 28.3$ & $985.0 \pm 148.7$ \\
\hline \multirow[t]{2}{*}{ Big city } & $75.2 \pm 16.9$ & $157.2 \pm 21.2$ & $561.7 \pm 99.4$ \\
\hline & $p<0.01$ & $p=0.04$ & $p=0.11$ \\
\hline Age & $\begin{array}{c}\rho=0.1 \\
p=0.48\end{array}$ & $\begin{array}{l}\rho=0.07 \\
p=0.63\end{array}$ & $\begin{array}{l}\rho=0.07 \\
p=0.64\end{array}$ \\
\hline
\end{tabular}

Results presented as mean \pm standard error of mean, $r$-Pearson's correlation coefficient.

pared to healthy controls. Interestingly, a trend toward lower levels of sensory thresholds was observed in lesional AD skin compared to non-lesional one. Patients with psoriasis also showed higher sensory threshold levels when compared to the control group. They also demonstrated higher threshold levels within lesional psoriatic skin when compared to lesional AD skin $(p<0.01)$. In contrast to $A D$, patients with psoriasis demonstrated a higher sensory threshold level at $250 \mathrm{~Hz}$ and $2000 \mathrm{~Hz}$ within lesional skin compared to non-lesional one (Table 3).

Regarding patients with $A D$, there was no significant correlation between the sensory threshold level and dis-
Table 3. Mean sensory threshold levels $(\mu \mathrm{A})$ for different current frequencies in healthy subjects

\begin{tabular}{|c|c|c|c|}
\hline \multirow[t]{2}{*}{ Parameter } & \multicolumn{3}{|c|}{ Current frequency } \\
\hline & $5 \mathrm{~Hz}$ & $250 \mathrm{~Hz}$ & $2000 \mathrm{~Hz}$ \\
\hline \multicolumn{4}{|l|}{ Atopic dermatitis: } \\
\hline Lesional skin & $293.2 \pm 72.1$ & $378.9 \pm 103.6$ & $1129.8 \pm 171.7$ \\
\hline \multirow{2}{*}{$\begin{array}{l}\text { Non-lesional } \\
\text { skin }\end{array}$} & $487.3 \pm 87.2$ & $546.4 \pm 80.6$ & $1584.9 \pm 193.8$ \\
\hline & $p=0.06$ & $p=0.14$ & $p=0.06$ \\
\hline \multicolumn{4}{|l|}{ Psoriasis: } \\
\hline Lesional skin & $693.1 \pm 161.2$ & $887.5 \pm 182.2$ & $2048.4 \pm 207.1$ \\
\hline \multirow{2}{*}{$\begin{array}{l}\text { Non-lesional } \\
\text { skin }\end{array}$} & $681.1 \pm 192.3$ & $586.6 \pm 153.4$ & $1435.5 \pm 156.7$ \\
\hline & $p=0.92$ & $p=0.01$ & $p=0.001$ \\
\hline Healthy controls & $118.1 \pm 25.5$ & $192.9 \pm 24.5$ & $687.1 \pm 86.0$ \\
\hline
\end{tabular}

Results demonstrated as mean \pm standard error of mean, $r$-Pearson's correlation coefficient.

ease duration, duration of the current $A D$ exacerbation and disease severity according to SCORAD (Table 4). Similarly to AD, no significant correlations were found in psoriasis patients in regard to disease duration, duration of current disease exacerbation and psoriasis severity assessed with PASI (Table 4).

\section{Relationship between sensory threshold} and perception of pruritus

The intensity of pruritus at the time of examination was similar between AD and psoriasis patients (mean VAS $_{\text {current }}: 3.6 \pm 0.7$ points vs. $3.4 \pm 0.5$ points, respective-

Table 4. Correlations between selected clinical parameters and sensory thresholds in patients with atopic dermatitis and psoriasis

\begin{tabular}{|c|c|c|c|c|c|c|}
\hline \multirow[t]{2}{*}{ Variables } & \multicolumn{3}{|c|}{ Atopic dermatitis } & \multicolumn{3}{|c|}{ Psoriasis } \\
\hline & $5 \mathrm{~Hz}$ & $250 \mathrm{~Hz}$ & $2000 \mathrm{~Hz}$ & $5 \mathrm{~Hz}$ & $250 \mathrm{~Hz}$ & $2000 \mathrm{~Hz}$ \\
\hline \multicolumn{7}{|l|}{ Disease duration: } \\
\hline Lesional skin & $\begin{array}{l}\rho=0.01 \\
p=0.97\end{array}$ & $\begin{array}{c}\rho=-0.07 \\
p=0.8\end{array}$ & $\begin{array}{c}\rho=-0.01 \\
p=0.98\end{array}$ & $\begin{array}{l}\rho=0.3 \\
p=0.21\end{array}$ & $\begin{array}{l}\rho=0.14 \\
p=0.56\end{array}$ & $\begin{array}{l}\rho=0.14 \\
p=0.55\end{array}$ \\
\hline Non-lesional skin & $\begin{array}{c}\rho=-0.05 \\
p=0.85\end{array}$ & $\begin{array}{c}\rho=-0.27 \\
p=0.27\end{array}$ & $\begin{array}{c}\rho=-0.14 \\
p=0.58\end{array}$ & $\begin{array}{c}\rho=-0.04 \\
p=0.87\end{array}$ & $\begin{array}{c}\rho=-0.06 \\
p=0.79\end{array}$ & $\begin{array}{c}\rho=-0.14 \\
p=0.54\end{array}$ \\
\hline \multicolumn{7}{|c|}{ Duration of the current disease exacerbation: } \\
\hline Lesional skin & $\begin{array}{c}\rho=-0.34 \\
p=0.18\end{array}$ & $\begin{array}{c}\rho=-0.36 \\
p=0.16\end{array}$ & $\begin{array}{l}\rho=-0.2 \\
p=0.45\end{array}$ & $\begin{array}{l}\rho=0.02 \\
p=0.94\end{array}$ & $\begin{array}{c}\rho=-0.07 \\
p=0.77\end{array}$ & $\begin{array}{l}\rho=0.12 \\
p=0.63\end{array}$ \\
\hline Non-lesional skin & $\begin{array}{c}\rho=-0.19 \\
p=0.47\end{array}$ & $\begin{array}{c}\rho=-0.37 \\
p=0.14\end{array}$ & $\begin{array}{l}\rho=0.08 \\
p=0.77\end{array}$ & $\begin{array}{c}\rho=-0.03 \\
p=0.91\end{array}$ & $\begin{array}{c}\rho=-0.11 \\
p=0.63\end{array}$ & $\begin{array}{l}\rho=0.19 \\
p=0.42\end{array}$ \\
\hline \multicolumn{7}{|c|}{ Disease severity (SCORAD/PASI): } \\
\hline Lesional skin & $\begin{array}{l}\rho=0.15 \\
p=0.54\end{array}$ & $\begin{array}{c}\rho=0.1 \\
p=0.68\end{array}$ & $\begin{array}{l}\rho=0.4 \\
p=0.1\end{array}$ & $\begin{array}{l}\rho=-0.1 \\
p=0.67\end{array}$ & $\begin{array}{c}\rho=-0.14 \\
p=0.57\end{array}$ & $\begin{array}{c}\rho=-0.22 \\
p=0.35\end{array}$ \\
\hline Non-lesional skin & $\begin{array}{l}\rho=0.18 \\
p=0.48\end{array}$ & $\begin{array}{l}\rho=0.22 \\
p=0.38\end{array}$ & $\begin{array}{l}\rho=0.14 \\
p=0.58\end{array}$ & $\begin{array}{c}\rho=-0.16 \\
p=0.5\end{array}$ & $\begin{array}{c}\rho=-0.25 \\
p=0.28\end{array}$ & $\begin{array}{c}\rho=-0.33 \\
p=0.15\end{array}$ \\
\hline
\end{tabular}

$\rho$-Spearman's correlation coefficient. 
ly, $p=0.87)$. However, maximal itch intensity as well as pruritus scoring according to the itch questionnaire was slightly higher in AD patients than in psoriasis individuals (mean VAS max $_{0.4} 6.6$ points vs. $4.8 \pm 0.6$ points, respectively, $p=0.07$; mean itch questionnaire scoring: $15.2 \pm 0.9$ points vs. $12.0 \pm 1.0$, respectively, $p=0.02$ ).

Regarding the sensory threshold for electric stimuli and intensity of pruritus we found that itch severity significantly correlated with the sensory thresholds for the current frequency of $5 \mathrm{~Hz}$ (Table 5). Significant correlations were also observed for itch questionnaire and sensory thresholds for $250 \mathrm{~Hz}$ and $2000 \mathrm{~Hz}$, but the correlation coefficient was lower than for $5 \mathrm{~Hz}$ (Table 5).

\section{Discussion}

In this study we exposed 49 healthy volunteers, 18 patients with $A D$ and 20 with psoriasis to alternating current stimulation with frequencies ranging from $5 \mathrm{~Hz}$ to $2000 \mathrm{~Hz}$ by using a current source constructed specially for this research. Based on achieved results it could be supposed that measurement of the sensory threshold might be a valuable, additional tool for the valid assessment of pruritus. However, several issues should be solved in the future prior to more widely employment of such devices in routine clinical settings. Unexpectedly, we found higher sensory thresholds in patients with $A D$ or psoriasis than in healthy controls. These results are partly contradictory to some previously published reports. Kobayashi et al. [11] observed that patients with AD showed a lower barrier function and lower current perception threshold than normal individuals and the current perception threshold was found to be inversely correlated with transepidermal water loss levels. However, not all studies were able to demonstrate current threshold lowering in patients with AD and these discrepancies must be explained in the future. Ikoma et al. [16] did not find any difference between healthy subjects and AD patients regarding their response to electrical $(0.08-8 \mathrm{~ms}, 2-200 \mathrm{~Hz})$ and chemical (histamine iontophoresis; 100 microC) stim- uli. Accordingly, Mori et al. [24] observed no statistically significant difference in the current perception threshold among extrinsic $A D$, intrinsic $A D$ and normal controls. In contrast, our group found an even increased sensory threshold to current stimulation in patients with $A D$ or psoriasis. Our findings are in accordance with the study by Yudina et al. [13] who documented elevated thermal thresholds in patients with AD. It is possible that the obtained results are influenced by the shape of the excitation current waveform. Other authors used sinusoidal [11, $24]$ or pulse $[13,16]$ excitation signal while in our study it was a bipolar square wave with duty cycle of 0.5. An increased threshold for electric stimuli in AD or psoriasis patients may be related to the thickening of epidermis, especially stratum corneum, a phenomenon frequently observed in these entities. This might cause that the current density varied in the subsequent layers of the electrically stimulated skin. Probably, majority of the current flew through upper epidermis layers while bypassing lower epidermis layers and dermis. As a consequence, a lower current perception threshold was observed in psoriasis and AD patients. Furthermore, patients with $A D$ or psoriasis frequently apply various topical formulations to improve the skin condition. Although we have always cleaned the evaluated skin area prior to examination with alcohol, we cannot exclude that long-term application of emollients, which is frequently observed in this group of patients, might significantly alter the current conduction in the outer layers of epidermis.

One of the most relevant findings of our study was the significant correlation of the sensory threshold for $5 \mathrm{~Hz}$ with itch intensity. It is believed that the alternate current of $5 \mathrm{~Hz}$ mostly stimulates sensory C-fibres [30]. These nerve fibres are also thought to be the most important for conduction of itch stimuli. Having this in mind it could be supposed that with $5 \mathrm{~Hz}$ current we might test the excitation threshold of cutaneous $\mathrm{C}$ fibres. The lower the threshold is, the more severe pruritus the patient may experience. Thus, determination of the sensory threshold may be a valuable and objective examination

Table 5. Correlations between itch intensity and sensory thresholds in patients with atopic dermatitis and psoriasis

\begin{tabular}{lccc}
\hline Variables & $5 \mathrm{~Hz}$ & $250 \mathrm{~Hz}$ & $2000 \mathrm{~Hz}$ \\
\hline VAS $_{\text {current }}:$ & $\rho=-0.33, p=0.04$ & $\rho=-0.3, p=0.06$ & $\rho=-0.26, p=0.12$ \\
\hline \begin{tabular}{l} 
Lesional skin \\
\hline Non-lesional skin
\end{tabular} & $\rho=0.05, p=0.76$ & $\rho=-0.02, p=0.89$ & $\rho=0.05, p=0.75$ \\
\hline VAS $_{\text {max }}:$ & $\rho=-0.32, p<0.05$ & $\rho=-0.29, p=0.07$ & $\rho=-0.19, p=0.26$ \\
\hline $\begin{array}{l}\text { Lesional skin } \\
\text { Non-lesional skin }\end{array}$ & $\rho=0.09, p=0.59$ & $\rho=0.05, p=0.77$ & $\rho=0.21, p=0.22$ \\
\hline Itch questionnaire: & $\rho=-0.54, p<0.001$ & $\rho=-0.46, p<0.01$ & $\rho=-0.35, p=0.03$ \\
\hline Lesional skin & $\rho=-0.09, p=0.57$ & $\rho=-0.03, p=0.84$ & $\rho=0.15, p=0.38$ \\
\hline Non-lesional skin & & & \\
\hline
\end{tabular}

VAS - Visual Analogue Scale, $r$ - Pearson's correlation coefficient; statistically significant results marked in bold. 
during the assessment of pruritic dermatoses. Furthermore, it seems that at least some patients with chronic itch may demonstrate asmall nerve fibre dysfunction and measurement of the electric sensory threshold might be a valuable and promising adjunct diagnostic method for assessment of such patients. However, it should be underlined that a great variability of the sensory threshold between individual persons were also noted, which may hinder the proper interpretation of achieved results. Therefore, any reference ranges for sensory thresholds must be established with a great caution.

Interestingly, we also found that women had a significantly lower sensory threshold than men. Such finding might be explained by gender differences in the thickness of epidermis and, probably, by possible differences in cutaneous innervations. On the other hand, the differences between people living in the country and those living in the cities or towns can be caused by various work performed in different living places as well by different habits.

\section{Conclusions}

Our results confirmed previous suggestions that the most relevant population of nerve fibers conducting pruritic stimuli are unmyelinated $\mathrm{C}$-fibers that are selectively activated by the $5 \mathrm{~Hz}$ alternating current. Measurement of current sensory perception might be a valuable tool for the assessment of patients suffering from dermatological pruritus.

\section{Acknowledgments}

This study was supported by the scientific grant of Wroclaw Medical University Pbmn-39, K.C. and A.R. applied for a patent for the device used in the study (application P. 400563 (PK/1662/AW)).

\section{Conflict of interest}

The authors declare no conflict of interest.

\section{References}

1. Reich A, Hrehorów E, Szepietowski JC. Pruritus is an important factor negatively influencing the well-being of psoriatic patients. Acta Derm Venereol 2010; 90: 257-63.

2. Yosipovitch G, Goon AT, Wee J, et al. Itch characteristics in Chinese patients with atopic dermatitis using a new questionnaire for the assessment of pruritus. Int I Dermatol 2002; 41: 212-6.

3. Ograczyk A, Miniszewska J, Kępska A, Zalewska-Janowska A. Itch, disease coping strategies and quality of life in psoriasis patients. Postep Derm Alergol 2014; 31: 299-304.

4. Reich A, Szepietowski JC. Pruritus intensity assessment: challenge for clinicians. Exp Rev Dermatol 2013; 8: 291-9.

5. Stander S, Steinhoff M. Pathophysiology of pruritus in atopic dermatitis: an overview. Exp Dermatol 2002; 11: 12-24.
6. Urashima R, Mihara M. Cutaneous nerves in atopic dermatitis. A histological, immunohistochemical and electron microscopic study. Virchows Arch 1998; 432: 363-70.

7. Nakamura M, Toyoda M, Morohashi M. Pruritogenic mediators in psoriasis vulgaris: comparative evaluation of itch-associated cutaneous factors. Br I Dermatol 2003; 149: 718-30.

8. Taneda K, Tominaga M, Negi O, et al. Evaluation of epidermal nerve density and opioid receptor levels in psoriatic itch. Br J Dermatol 2011; 165: 277-84.

9. Negi O, Tominaga M, Tengara S, et al. Topically applied semaphorin 3A ointment inhibits scratching behavior and improves skin inflammation in NC/Nga mice with atopic dermatitis. J Dermatol Sci 2012; 66: 37-43.

10. Grönroos M, Reunala T, Kartamaa M, Pertovaara A. Altered skin sensitivity in chronic itch: role of peripheral and central mechanisms. Neurosci Lett 1997; 228: 199-202.

11. Kobayashi H, Kikuchi K, Tsubono Y, Tagami H. Measurement of electrical current perception threshold of sensory nerves for pruritus in atopic dermatitis patients and normal individuals with various degrees of mild damage to the stratum corneum. Dermatology 2003; 206: 204-11.

12. Ward RS, Tuckett RP, English KB, et al. Substance $P$ axons and sensory threshold increase in burn-graft human skin. J Surg Res 2004; 118: 154-60.

13. Yudina MM, Toropina GG, Lvov A, Gieler U. Innovative neurophysiological methods in itch research: long-latency evoked potentials after electrical and thermal stimulation in patients with atopic dermatitis. Acta Derm Venereol 2011; 91: 656-9.

14. Ikoma A, Fartasch M, Heyer G, et al. Painful stimuli evoke itch in patients with chronic pruritus: central sensitization for itch. Neurology 2004; 62: 212-7.

15. Tuckett R. Itch evoked by electrical stimulation of the skin. J Invest Dermatol 1982; 79: 368-73.

16. Ikoma A, Handwerker H, Miyachi Y, Schmelz M. Electrically evoked itch in humans. Pain 2005; 113: 148-54.

17. Kiso T, Nagakura Y, Toya T, et al. Neurometer measurement of current stimulus threshold in rats. J Pharmacol Exp Ther 2001; 297: 352-6.

18. Pitei DL, Watkins PJ, Stevens MJ, Edmonds ME. The value of the Neurometer in assessing diabetic neuropathy measurement of the current perception threshold. Diabet Med 1994; 11: 872-6.

19. Katims JJ. Neuroselective current perception threshold quantitative sensory test. Muscle Nerve 1997; 20: 1468-9.

20. Lengyel C, Torok T, Varkonyi T, et al. Baroreflex sensitivity and heart-rate variability in insulin-dependent diabetics with polyneuropathy. Lancet 1998; 351: 1436-7.

21. Masson EA, Boulton AJ. The Neurometer: validation and comparison with conventional tests for diabetic neuropathy. Diabet Med 1991; 8: S63-6.

22. Matsumoto M, Inoue $M$, Hald A, et al. Characterization of three different sensory fibers by use of neonatal capsaicin treatment, spinal antagonism and a novel electrical stimulation-induced paw flexion test. Molecular Pain 2006; 2: 16.

23. Kiso T, Nagakura Y, Toya T, et al. Selective activation of primary afferent fibers evaluated by sine-wave electrical stimulation. Mol Pain 2005; 1: 13.

24. Mori T, Ishida K, Mukumoto S, et al. Comparison of skin barrier function and sensory nerve electric current perception threshold between IgE-high extrinsic and IgE-normal intrinsic types of atopic dermatitis. Br J Dermatol 2010; 162: 83-90.

25. Severity scoring of atopic dermatitis: the SCORAD index. Consensus Report of the European Task Force on Atopic Dermatitis. Dermatology 1993; 186: 23-31. 
26. Fredriksson T, Pettersson U. Severe psoriasis: oral therapy with a new retinoid. Dermatologica 1978; 157: 238-44.

27. Furue M, Ebata T, Ikoma A, et al. Verbalizing extremes of the visual analogue scale for pruritus: a consensus statement. Acta Derm Venereol 2013; 93: 214-5.

28. Reich A, Heisig M, Phan NQ, et al. Visual analogue scale: evaluation of the instrument for the assessment of pruritus. Acta Derm Venereol 2012; 92: 497-501.

29. Muszer K, Reich A. Creation and validation of the questionnaire for assessment of itch severity. II International Students' Conference of Young Medical Researchers, Wrocław, 13-14.04.2012, Abstract book p. 203.

30. Koga K, Furue H, Rashid H, et al. Selective activation of primary afferent fibers evaluated by sine-wave electrical stimulation. Mol Pain 2005; 1: 13. 